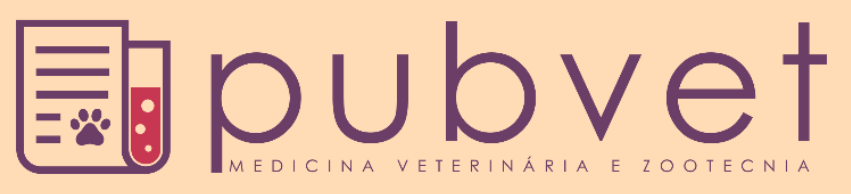

ISSN $1982-1263$

https://doi.org/10.31533/pubvet.v14n3a528.1-6

\title{
Intrauterine infusion reduces inflammatory status and could be increased the embryo recovery in mares with chronic endometritis
}

\author{
Ludimila Cardoso Zoccal Janini ${ }^{a^{*}} \odot \mathbb{D}$, Edjalma Rodrigues da Silva-Junior ${ }^{\mathrm{b}} \bullet \mathbb{( D}$, Stella Maris

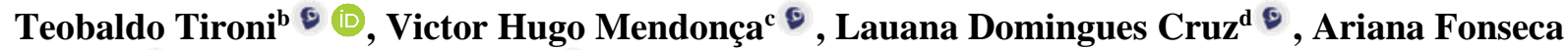 \\ $\operatorname{Ramos}^{\mathrm{Q}}$, , Rafael Silva Cipriano ${ }^{\mathrm{Q}}$ (D) \\ ${ }^{a}$ Master student in Animal Biotechnology, Veterinary Medicine and Animal Science College - São Paulo State University, Botucatu, São Paulo, Brazil \\ ${ }^{b}$ Doctor student in Animal Biotechnology, Veterinary Medicine and Animal Science College - São Paulo State University, Botucatu, São Paulo, Brazil \\ ${ }^{c}$ Araçá Animal Reproduction Central, Marechal Rondon Highway, 527 Km, Araçatuba, São Paulo. \\ ${ }^{d}$ Veterinary, Salesian Catholic University Center Auxilium (UniSALESIANO) Araçatuba, São Paulo, Brasil. \\ ${ }^{e}$ Veterinary Medicine Professor - Salesian Catholic University Center Auxilium (UniSALESIANO) Araçatuba, São Paulo, Brasil, \\ *Corresponding for Author, E-mail: ludi.zoccal@hotmail.com
}

\begin{abstract}
Endometritis, which refers to chronic inflammation of the superficial layers of the uterus, is caused by a failure of the defense mechanism to eliminate antigens, and is a common cause of infertility in mares. Therefore, ultrasound examination is essential during diagnosis to perform the differentials. Typically, treatments that cleanse the uterus are used to treat endometritis and are they also beneficial in mare reproduction. However, alternative therapies, which are less expensive, are needed for the treatment of this disease. Taking this into account, ozone gas was used to control the microorganisms associated with this disease (virus, bacteria, and fungi). Thus, the aim of this study was to investigate the efficiency of ozonized Lactated Ringer's Solution (LRS) infused into the uterus, as an alternative therapy for recurrent endometritis. Five animals $(n=5)$ with previous reproductive issues were treated during the estrus phase with ozonized Lactated Ringer's Solution. Cytology, microbiology, and uterine and ovarian ultrasound examinations were performed to evaluate uterine edema and follicular dynamics. At the end of the treatment, $20 \%$ of the animals showed positive results in embryo recovery. Such improvement in embryo recovery is the caused by the decrease in polymorphonuclear cells and the absence of infection by microorganisms in the uterus. In some mares, it was possible to observe a recovery in embryo production despite a history of infertility. Therefore, the use of ozone in the uterus could modulate inflammatory responses to increase embryo recovery in mares with fertility problems.
\end{abstract}

Keywords: endometrium, inflammation, ozone therapy, treatment, uterus

\section{Introduction}

Brazil stands out as the home to the third largest equine population in the world (FAPRI, 2019), and this is reflected in the number of embryo transfers in the country. In Brazil alone, approximately 25,000 embryo transfers occur per year, which corresponds to $50 \%$ of total embryo transfers in the world (Losinno \& Urosevic, 2015).

Fertile mares typically have no uterine infections; however, coitus or artificial insemination may cause infections. Physical barriers, such as anatomical malformations; and immune system defenses, such as cellular immunity (Mari et al., 2005), can eliminate all undesirable elements, facilitating the uterine environment to safely receive the spermatozoa, and consequently fertilize the embryo (Christoffersen et al., 2015; LeBlanc \& Causey, 2009; Troedsson et al., 1995). Nevertheless, in some mares, these defense mechanisms are ineffective and they become susceptible to developing endometritis (Canisso et al., 2016; Ferris, 2016). 
Mares with endometritis can present many etiologies, but the inflammation generally does not extend beyond the inner layers of the reproductive tract, except in postpartum mares. Common signs of endometritis include inflammation of the uterus, intrauterine fluid accumulation, inflammatory endometrial cytological patterns, and thickening of the uterine mucosa. However, the etiological agents should be identified, and positive results from microbiological cultures are not considered appropriate evidence for the pathology. In some mares, the uterine fluid prior to natural mating or artificial insemination (AI) does not show bacterial infection. However, this uterine fluid is still capable of acting as a culture medium for microorganisms that might enter the uterus and, consequently decrease spermatozoa survival and later embryo survival as well (Canisso et al., 2016; Ferris, 2016; LeBlanc \& Causey, 2009; Nielsen et al., 2010).

The traditional treatments for endometritis could decrease embryo recovery because of the infusion of caustic substances into the uterus. Alternatively, the use of ozone therapy (OT) is a potential treatment with fewer collateral effects in the uterus (Merhi et al., 2019). In veterinary medicine, the main therapeutic applications of OT in equines are related to the healing and disinfection of extensive wounds in ischemic lesions (Merhi et al., 2019; Penido et al., 2010), and this gas is also applied in locomotor limb pathologies (Haddad et al., 2009).

Thus, the aims of this study were to evaluate the efficiency of ozonized Lactated Ringer's Solution (LRS) in the treatment of endometritis in mares before AI and verify if it could improve embryo recovery and reduce inflammatory response in the uterus.

\section{Material and methods}

The experiment was carried out at a breeding center for horses, in the north western region of São Paulo State, and was approved by the Ethical Committee on the Use of Animals of the Salesian Catholic University Centre Auxilium under Protocol No. 36/2017.

Five Quarter Horse embryo-donor mares were used $(n=5)$, with a mean age of 17 years $(S D=6.4)$ and mean body score of 4 , according to the scale of $0-5$ proposed by Henneke et al. (1983). These animals were clinically healthy but had unsatisfactory embryo recovery rates - less than $20 \%$ for at least the previous five mounting seasons. Cytological and microbiological examinations compatible with endometritis were performed by ultrasound.

Previously, the animals were treated with conventional intrauterine lavage LRS, and 5 IU oxytocin was administered intravenously to induce contractions in order to remove intrauterine fluid mechanically. Furthermore, intrauterine infusions of antibiotics and systemic antibiotics application treatments were used to quell any infections. However, none of the therapies were successful.

In July, the animals received artificial lighting from nightfall until 23:00 $\mathrm{h}$ to modify the photoperiod and influence the neuroendocrine system through the hypothalamic-pituitary-gonadal axis in order to stimulate the recovery of ovarian activity.

Five mares with signs of endometritis were used. First, they were included in the control group. Then, in the next estrous cycle, the same animals were subjected to ozone treatment.

Ultrasound examinations were performed every $24 \mathrm{~h}$ to determine the degree of uterine edema on a scale $0-3$, according to Samper (2009), and the diameter of the dominant follicle (DF) was measured in cross shape using ultrasound (Mindray Dp 2200 vet ${ }^{\circledR}$ ) with $5.0 \mathrm{MHz}$ transrectal probe.

When the uterine edema was around grade 3 and the dominant follicle had a diameter $\geq 35 \mathrm{~mm}$, ovulation was induced using deslorelin (Sincrorrelin ${ }^{\circledR}$, Ourofino, $0.9 \mathrm{mg} / \mathrm{animal} / \mathrm{IM}$ ) in combination with human chorionic gonadotrophin hCG (Vetecor ${ }^{\circledR}$, Hertape Calier, 2,500 IU/animal/EV). Samples from the uterus were collected for microbiological and cytological examination. Uterine lavage was performed with $3 \mathrm{~L} \mathrm{LRS}$ with ozone, $1 \mathrm{~L}$ at a time, allowing it to remain in the uterus for $5 \mathrm{~min}$ and then withdrawing it. The next day, AI was performed. A second uterine lavage was performed to remove non-viable spermatozoa $24 \mathrm{~h}$ after the AI. The semen used was of commercial origin, and previous tests had proven its fertility. 
The control group was submitted to the same process as the treatment group, but the lavages were carried out with conventional LRS. In the subsequent estrus, cytological and microbiological examinations were performed again to evaluate the previous treatment. The schematic in Figure 1 demonstrates the protocol used during the experiment.

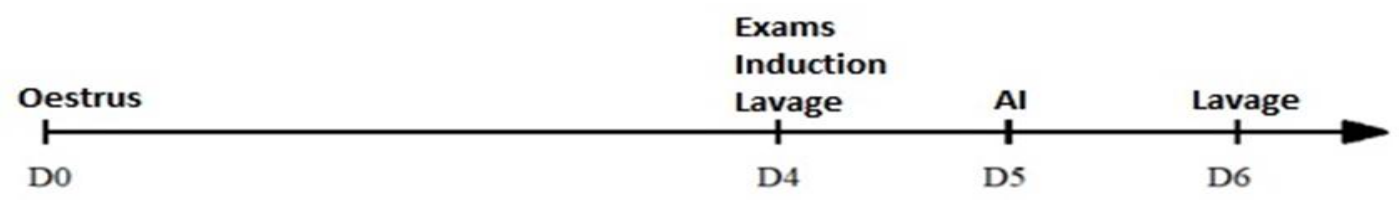

Figure 1. Scheme representative of the timeline used for the experiment. D0: day 0; D4: day 4; D5: day 5; D6: day 6; AI: artificial insemination

For the collection of cytological material and microbiological samples, lavage and disinfection of the vulva and perineal region were performed with water, neutral detergent, and $70 \%$ alcohol. Sterile intravaginal swabs were introduced through the cervix into the uterus, where, in contact with the wall of the uterus, 15 rotational movements were completed to collect the samples. After collection, the swabs were packed in Stuart transport medium, identified, and then sent to the laboratory for the microbiological examination.

Microbiological cultures were performed on slides containing Agar base plus 8\% (v/v) defibrinated sheep blood and Levine agar. Growth characteristics of plate colonies, such as hemolysis production, pigment, and morphological characteristics, were observed by the Gram staining method.

In the cytological examination, a cervical gynecological brush (Kolplastic ${ }^{\circledR}$ Ltda. - Itupeva-SP) was used, and the procedure used for sample collection was similar to that using swabs. Immediately after collection, smears of the material were prepared on slides, fixed, and analyzed by the Panoptic technique. Cellular characteristics were evaluated according to Rua et al. (2016), in which the presence of more than one polymorphonuclear cell in 10 endometrial cells is considered endometritis. The cytological samples were classified according to McKinnon et al. (2011), as observed in Table 1.

Table 1. Degree of uterine inflammation by cytological exam

\begin{tabular}{lc}
\hline Inflamatory Cells (\%) & Endometritis Classification \\
\hline $0-3 \%$ & Normal to oestrous \\
$3-10 \%$ & Mild endometritis \\
$10-30 \%$ & Moderate endometritis \\
$30-50 \%$ & Moderate to severe endometritis \\
$50-70 \%$ & Severe endometritis \\
$>70 \%$ & Very severe endometritis \\
\hline
\end{tabular}

Thereafter, a second lavage and disinfection of the perineal region was performed. A two-way Foley probe 22 was introduced into the uterus through the cervix, and then it was fixed with $40 \mathrm{~mL}$ air.

An IV set was connected to the ozone generating machine (model Z400, Ozonebras MEHCA Assembly and Maintenance of Home Health Care Equipment LTDA EPP) with $5 \mathrm{~g} / \mathrm{O}_{3} /$ hour capacity, supplied by an oxygen cylinder with $1.5 \mathrm{kgf} / \mathrm{cm}^{2}$ pressure and a flowmeter maintained at $1.5 \mathrm{kgf} / \mathrm{cm}^{2}$ pressure into the LRS. After swirling for 5 min to allow the medium to become ozonized, the LRS was immediately infused into the uterus with the aid of a Foley probe. This ozonization process was carried out in 3 L LRS at each lavage.

Finally, this preparation of LRS and ozone was infused in the uterus, where it was allowed to remain for $5 \mathrm{~min}$ before being removed.

\section{Results and discussion}

During the experiment, the animals presented no clinical signs of discomfort or any treatment-related side effects. 
The pre-ozonization cytological examination showed that $60 \%$ of the mares had some degree of inflammation in the endometrium. Only one mare (animal 4) had polymorphonuclear leukocytes (PMN) in the slide post-treatment, but with a significant decrease, as shown in Table 2 and Figure 2 . The degree of endometrial inflammation was classified according to McKinnon et al. (2011), being determined by the percentage of neutrophils present in the cytological sample. The degree of endometritis was associated with the history and evolution time of the reproductive issue. Even in mild cases of endometritis, the animals showed lower embryo recovery rates in at least the last five mounting seasons.

Table 2. Cytological exam in mares $(n=5)$ with endometritis before and after treatment with OT

\begin{tabular}{lcccc}
\hline & \multicolumn{2}{c}{ Day 0 Pre-treatment } & \multicolumn{2}{c}{ Day 0 Post-treatment } \\
\cline { 2 - 5 } Animals & Inflammatory Cells (\%) & Endometritis Classification & Inflammatory Cells (\%) & Endometritis Classification \\
\hline 1 & 5 & Mild & 1 & Normal \\
2 & 1.5 & Normal & 1.3 & Normal \\
3 & 4 & Mild & 0.2 & Normal \\
4 & 70 & Very severe & 1.5 & Mild \\
5 & 1.4 & Normal & 0.6 & Normal \\
\hline
\end{tabular}

There was a decrease in inflammatory cells in the cytological examination after the use of LRS with ozone. The average reduction accounted for approximately $52 \%$ of these cells per field in the slide. Ozone has been shown to be effective in the treatment and prevention of diseases is known to have bactericidal (Moureu et al., 2015), fungicidal, and viricidal effects. These effects are achieved through the actions of reactive species of oxygen and lipid oxidation products; in addition, it can be administered in several ways. Microbiological culture tests indicated that $60 \%$ of the mares showed the presence of bacteria inside the uterus, with Escherichia coli and Klebsiela spp. as the predominant species.
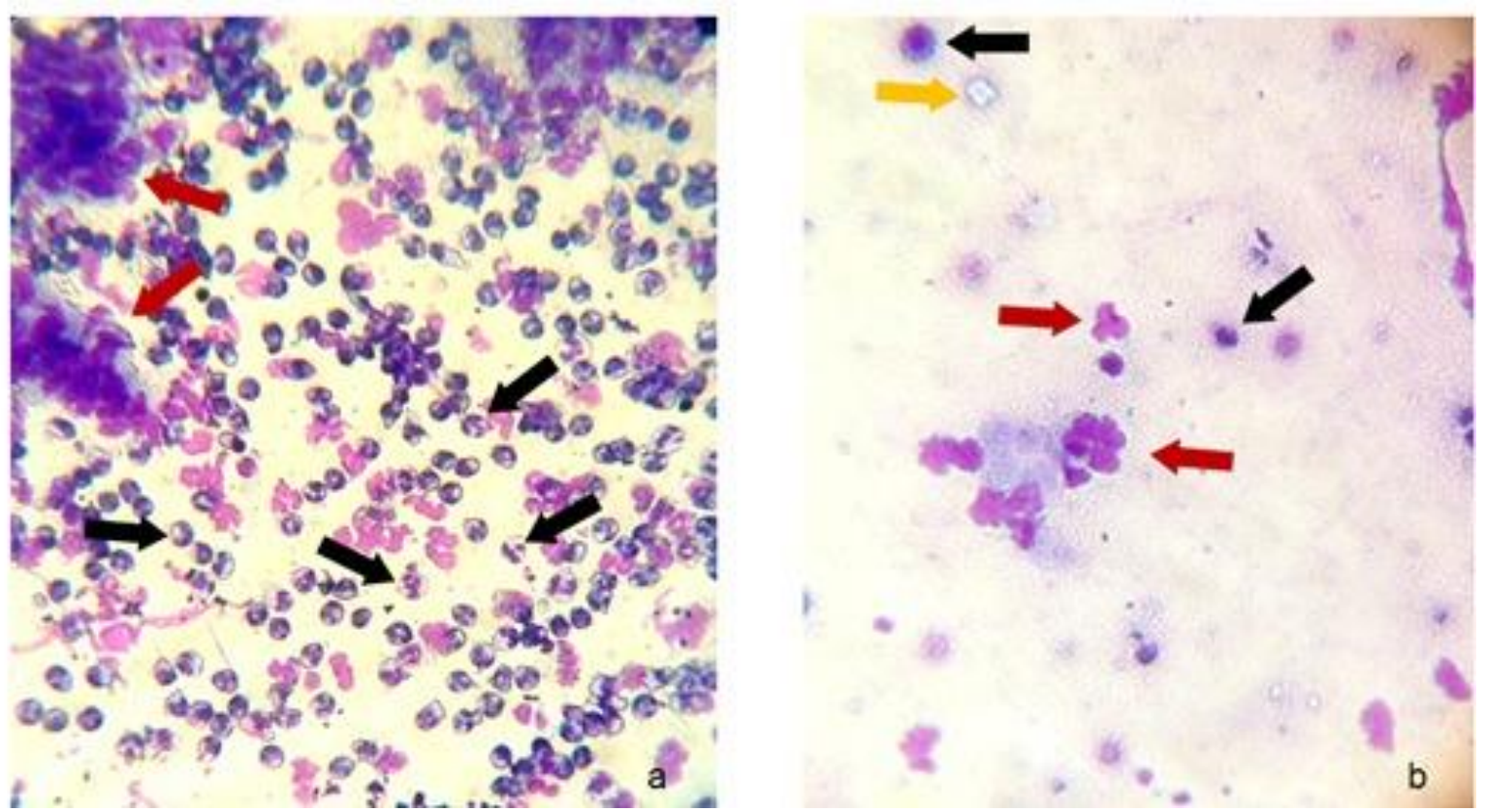

Figure 2. Cytological aspects of endometritis in animal 4. a) Endometrial cytology on the 4th day after the beginning of oestrus, classified as very severe endometritis; large number of PMN (40x), HE staining. b) Endometrial cytology after treatment on the 4th day after the beginning of the subsequent oestrus (40x), HE staining. Black arrows indicate PMN; red arrows indicate degenerative cells; yellow arrow indicates erythrocyte.

In the subsequent estrus, no animals showed bacterial growth in the microbiological examination and $20 \%$ of them $(\mathrm{n}=1)$ presented with mild endometritis in the cytological examination. In the control group, $80 \%$ of the mares presented bacterial growth. This result did not change after washing with nonozonized LRS, which is the most common treatment for endometritis in mares (Canisso et al., 2016).

In addition, the reaction of $\mathrm{O}_{3}$ with unsaturated fatty acids produced substances that act on oxyhemoglobin, release oxygen, and increase their availability in the tissues, thus contributing to 
regeneration (Mehlman \& Borek, 1987), which explains the data observed in this study. There was an increase in the number of uterine peeling cells in the lavages performed 8 days after AI for embryo recovery, whereas this was not the case in the subsequent lavages in the same mounting season.

Grade 3 uterine edema prior to treatment was present in all mares, while in the subsequent estrus, there was no change in this index.

All mares tested had a history of embryo recovery rates lower than $20 \%$ for at least the last five breeding seasons, with no change in the technical staff or in the control and collection methods over those years. Ozone improved the rate of embryo recovery in the mares treated, as positive results were obtained in $40 \%(\mathrm{n}=2)$; one mare produced an embryo in the estrous cycle treated with $\mathrm{O}_{3}$ and another animal produced an embryo in the subsequent estrous cycle (Table 3 ).

Table 3. Result of embryo recovery lavages in the ozone-treated mares

\begin{tabular}{lcccc}
\hline Animals & Pre-treatment & Control group & Treated group & Post-treatment \\
\hline 1 & Absent & Absent & Absent & + \\
2 & Absent & Absent & Absent & Absent \\
3 & Absent & Absent & Absent & Absent \\
4 & Absent & Absent & Absent & Absent \\
5 & Absent & Absent & + & Absent \\
\hline
\end{tabular}

The symbol "+" means presence of embryo

Following AI, intrauterine fluid accumulation with measurements smaller than $2 \mathrm{~cm}$ in diameter were observed on ultrasound; this accumulation is considered a more controlled physiological inflammatory response after semen deposition (Nielsen et al., 2010). It has been reported that the use of $\mathrm{O}_{3}$ improves anemia and blood circulation by increasing the elasticity and permeability of erythrocytes (Penido et al., 2010), which explains why all animals under OT presented with a reduction in the amount of fluid, from grade 3 to grade 1 ( $0-3$ scale) after treatment. In the control animals, the degree of fluid accumulation did not change.

Uterine lavage is considered to be the best form of physical cleansing and can be done by simple siphoning. This technique results in better pregnancy rates in mares with a history of persistent post-breeding endometritis (Haddad et al., 2009). In comparison to the conventional lavage performed in the control group, lavage with ozonized LRS showed a reduction in the amount of fluid and a decrease in the number of inflammatory cells, as observed in the cytology slides.

\section{Conclusions}

Ozone therapy was effective for mares with endometritis, resulting in a reduction in polymorphonuclear cells in cytological examinations, as well as in the number of microorganisms in microbiological examinations. In addition, the animals treated with intrauterine ozone showed an improvement in fertility, indicating the recovery of embryo production in mares with chronic endometritis. More research on OT in the treatment of endometritis is recommended to enable researchers to determine the most appropriate treatment period and concentration required to increase embryo production in mares affected by chronic endometritis.

\section{Acknowledgements}

The Central Araçá Animal Reproduction, for granting us the animals for research.

\section{Conflict of Interest Statement}

The authors of this work declare that there is no conflict of interest.

\section{References bibliographies}

Canisso, I. F., Stewart, J., \& Silva, M. A. C. (2016). Endometritis: managing persistent post-breeding endometritis. Veterinary Clinics: Equine Practice, 32(3), 465-480. 
https://doi.org/https://doi.org/10.1016/j.cveq.2016.08.004.

Christoffersen, M., Brandis, L., Samuelsson, J., Bojesen, A. M., Troedsson, M. H. T., \& Petersen, M. R. (2015). Diagnostic double-guarded low-volume uterine lavage in mares. Theriogenology, 83(2), $222-227$.

FAPRI. (2019). Food and Agricultural Policy Research Institute (W. A. O. Database (ed.)). Food and Agricultural Policy Research Institute; Iowa State University and University of Missouri-Columbia . http://www.fapri.iastate.edu/tools/outlook.aspx

Ferris, R. A. (2016). Endometritis: Diagnostic tools for infectious endometritis. Veterinary Clinics: Equine Practice, 32(3), 481-498. https://doi.org/https://doi.org/10.1016/j.cveq.2016.08.001.

Haddad, M. A., Souza, M. V, Hincapie, J. J., Ribeiro Junior, J. I., Ribeiro Filho, J. D., \& Benjamin, L. A. (2009). Comportamento de componentes bioquímicos do sangue em equinos submetidos à ozonioterapia. Arquivo Brasileiro de Medicina Veterinaria E Zootecnia, 61(3), 539-546. https://doi.org/http://dx.doi.org/10.1590/S0102-09352009000300003.

Henneke, D. R., Potter, G. D., Kreider, J. L., \& Yeates, B. F. (1983). Relationship between condition score, physical measurements and body fat percentage in mares. Equine Veterinary Journal, 15(4), 371-372. https://doi.org/http://dx.doi.org/10.1111/j.2042-3306.1983.tb01826.x.

LeBlanc, M. M., \& Causey, R. C. (2009). Clinical and subclinical endometritis in the mare: both threats to fertility. Reproduction in Domestic Animals, 44(3), 10-22. https://doi.org/http://dx.doi.org/10.1111/j.1439-0531.2009.01485.x.

Losinno, L., \& Urosevic, M. (2015). Equine embryo transfer. Technical and practical considerations for application on horse production programs. Review paper. 19th International Symposium on Animal Science (ISAS) and 20th International Congress on Biotechnology in Animal Reproduction, 23-30.

Mari, G., Barbara, M., Eleonora, I., \& Stefano, B. (2005). Fertility in the mare after repeated transvaginal ultrasound-guided aspirations. Animal Reproduction Science, 88(3), 299-308.

McKinnon, A. O., Squires, E. L., Vaala, W. E., \& Varner, D. D. (2011). Equine reproduction. John Wiley \& Sons.

Mehlman, M. A., \& Borek, C. (1987). Toxicity and biochemical mechanisms of ozone. Environmental Research, 42(1), 36-53.

Merhi, Z., Garg, B., Moseley-LaRue, R., Moseley, A. R., Smith, A. H., \& Zhang, J. (2019). Ozone therapy: a potential therapeutic adjunct for improving female reproductive health. Medical Gas Research, 9(2), 101-105. https://doi.org/http://dx.doi.org/10.4103/2045-9912.260652.

Moureu, S., Violleau, F., Haimoud-Lekhal, D. A., \& Calmon, A. (2015). Ozonation of sunflower oils: Impact of experimental conditions on the composition and the antibacterial activity of ozonized oils. $\begin{array}{lllll}\text { Chemistry and Physics of } & \text { 79-85. }\end{array}$ https://doi.org/https://doi.org/10.1016/j.chemphyslip.2015.01.004.

Nielsen, J. M., Troedsson, M. H., Pedersen, M. R., Bojesen, A. M., Lehn-Jensen, H., \& Zent, W. W. (2010). Diagnosis of endometritis in the mare based on bacteriological and cytological examinations of the endometrium: comparison of results obtained by swabs and biopsies. Journal of Equine Veterinary Science, 30(1), 27-30.

Penido, B. R., Lima, C. A., \& Ferreira, L. F. L. (2010). Aplicações da ozonioterapia na clínica veterinária. PUBVET, 4, Art-974.

Rua, M. A. S., Quirino, C. R., Bartholazzi Júnior, A., \& Barreto, M. A. P. (2016). Métodos diagnósticos de endometrite em éguas. PUBVET, 10, 873-945.

Samper, J. C. (2009). Equine breeding management and artificial insemination. St. Louis: Saunders Elsevier, 133-138.

Troedsson, M. H. T., Scott, M. A., \& Liu, I. K. (1995). Comparative treatment of mares susceptible to chronic uterine infection. American Journal of Veterinary Research, 56(4), 468-472.

Recebido: 03 de fevereiro, 2020.

Aprovado: 12 de março, 2020.

Publicado: 22 de abril, 2020.
Licenciamento: Este artigo é publicado na modalidade Acesso Aberto sob a licença Creative Commons Atribuição 4.0 (CC-BY 4.0), a qual permite uso irrestrito, distribuição, reprodução em qualquer meio, desde que o autor e a fonte sejam devidamente creditados. 